LA W RENCE LIVERMORE N A TIONAL LABORATORY
Eagle Nebula Experiments on NIF: NIF Facility Time Proposal

A. B. Cooper, B. A. Remington, M. W. Pound, A. S. Moore, S. A. Maclaren, R. J. Williams, D. D. Ryutov, M. E. Foord, J. C. Hayes, A. Mizuta

June 14, 2010 
This document was prepared as an account of work sponsored by an agency of the United States government. Neither the United States government nor Lawrence Livermore National Security, LLC, nor any of their employees makes any warranty, expressed or implied, or assumes any legal liability or responsibility for the accuracy, completeness, or usefulness of any information, apparatus, product, or process disclosed, or represents that its use would not infringe privately owned rights. Reference herein to any specific commercial product, process, or service by trade name, trademark, manufacturer, or otherwise does not necessarily constitute or imply its endorsement, recommendation, or favoring by the United States government or Lawrence Livermore National Security, LLC. The views and opinions of authors expressed herein do not necessarily state or reflect those of the United States government or Lawrence Livermore National Security, LLC, and shall not be used for advertising or product endorsement purposes.

This work performed under the auspices of the U.S. Department of Energy by Lawrence Livermore National Laboratory under Contract DE-AC52-07NA27344. 


\title{
Eagle Nebula Experiments on NIF: NIF Facility Time Proposal
}

\author{
A.B.R. Cooper, B.A. Remington, M.W. Pound, A.S. Moore, S.A. \\ Maclaren, R.J.R. Williams, D.D. Ryutov, M.E. Foord, J.C. Hayes, A. \\ Mizuta
}

\section{The Eagle Nebula and Radiatively Driven Molecular Clouds}

The Eagle Nebula, with its grand pillar structures, is one of the most captivating astronomical objects in the sky. ${ }^{1}$ The underlying dynamics of the Eagle Nebula are driven by the intense UV radiation from nearby bright young stars, which causes continuous photodissociation and ionization (i.e., ablation or photoevaporation) of the cloud surface layers. The resulting ablation pressure compresses the cloud and generates complex, radiative-hydrodynamic evolution, while the interior remains dense and very cold, due to very strong radiative cooling. A "force-free" magnetic field in the cloud's interior, described as "magnetostatic turbulence", is proposed as the source of the cloud's stiffness or resistance to compression. ${ }^{2}$ The Eagle Nebula, shown in Figure 1, is just one example of this common phenomenon of photoevaporation front dynamics in radiatively driven molecular clouds that occurs during the high mass star formation process.

There exist several models proposed to explain the origin of pillars in molecular clouds, such as in the Eagle Nebula. The earliest, suggested by Spitzer in $1954,{ }^{3}$ is based on the assumption that the (thin) cloud is being ablatively accelerated, which drives the Rayleigh-Taylor (RT) instability at the ablation front. The pillars are then identified with the familiar RT “spikes" of a heavy fluid penetrating into the lower density fluid. Another model relates formation of the pillars to the assumed presence of pre-existing dense "clumps" in the molecular cloud. ${ }^{4}$ The surrounding low density parts of the cloud are moved over a significant distance (ie, are "swept away") by the ablation pressure, whereas the shadowed parts behind the dense clumps remain relatively static, giving rise to the pillar structure.

A fundamental question presents itself. Do these pillars form as a consequence of radiative hydrodynamic instabilities (much like ablation front dynamics in inertial

\footnotetext{
1 J. Jeff Hester et al., "Hubble Space Telescope WFPC2 imaging of M16: photoevaporation and emerging young stellar objects”, Astron. J. 111, 2349 (1996).

2 D.D. Ryutov and B.A. Remington, "Scaling astrophysical phenomena to high-energy-density laboratory experiments”, Plasma Phys. Control. Fusion 44, B407 (2002).

${ }^{3}$ Spitzer, L., “Behavior of Matter in Space”, Ap.J., 120, 1 (1954).

${ }^{4}$ Kahn, F.D., “Collisions of two highly ionized clouds of gas”, Rev. Mod. Phys., 30, pp. 1069-1072, (1958).
} 


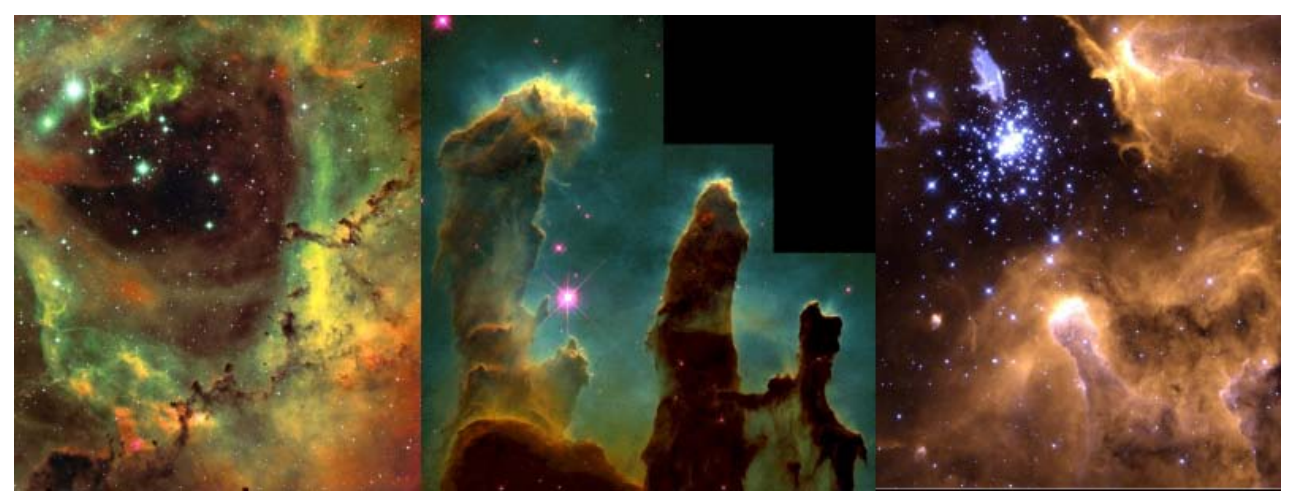

Figure 1: Just a few of the many examples of interstellar molecular pillars near young, hot stars. From left to right: Rosette Nebula, Eagle Nebula, NGC 3603.

confinement fusion) or as a result of pre-existing enhanced-density clumps in the cloud, or by some entirely different process? Answering these questions requires a more fundamental understanding of the dynamics in such radiatively driven molecular clouds.

During the last several years, our group has made significant progress in developing a theoretical model of the behavior of the photoevaporated clouds and developing an analysis method to compare our model predictions with astronomical observations. Our 2D hydrodynamic model of pillar formation includes energy deposition and release due to the absorption of UV radiation, recombination of hydrogen, radiative molecular cooling, magnetic pressure, and initial conditions based on astronomical observations of the Eagle Nebula. We have developed a theory for magnetostatic support in molecular clouds as well as a linear-regime model for photoevaporation front instability which takes into account acceleration of the front, temporal variation of the ionizing radiation intensity, the tilt of the radiation flux with respect to the surface normal, ${ }^{56}$ and partial absorption of incident radiation in the ablated material. To facilitate comparison between the model and astronomical observations, we have developed a process to create "synthetic observations" from the model by filtering it through the known telescope response function and processing the result in a manner identical to that used for the observations.

Given the daunting complexity of the nonlinear radiative hydrodynamics, however, no model of the Eagle Nebula can be viewed as conclusive in the absence of scaled

\footnotetext{
${ }^{5}$ D.D. Ryutov et al., "Phenomenological theory of the photoevaporation front instability", Astrophys. Space Sci., 307, 173 (2007).

${ }^{6}$ D.D. Ryutov et al., "Instability of an ablatively-accelerated slab in the case of non-normal irradiation", Plasma Phys. Control. Fusion 45, 769 (2003).
} 
validation experiments. With a scaled validation experimental component added to our project, we would be able to investigate the Eagle Nebula dynamics in all aspects, combining new astronomical observations, fundamental theory, 2D radiationhydrodynamics simulations, and scaled validation experiments. This would be an unprecedented achievement and a new paradigm in astrophysics research and methodology.

Such experiments would also be of great interest from a fundamental radiationhydrodynamics perspective. (1) Directional radiation is predicted to lead to a new class of "tilted radiation" instabilities not yet observed in the laboratory. ${ }^{6,7}$ (2) A setting where the ablated plasma is not optically thin to the driving radiation leads to a new RayleighTaylor stabilization mechanism. ${ }^{8}$ (3) To get RT-like instability growth requires entry into the deep nonlinear regime (i.e., tall columns), creating a very challenging and compelling radiation-hydrodynamics test bed. (4) Launched strong shocks encountering density enhancements could cause a strongly radiatively cooled clump crushing, which has never been studied before, and might itself be a seed for star formation.

We propose to develop and field an experimental design for a well-scaled NIF experiment to quantitatively test the models and 2D simulations of the Eagle Nebula dynamics deep into the nonlinear regime. The initial design is based on the Radiation Transport platform, and would use a half-hohlraum radiation cavity with a small, possibly tamped opening on the hohlraum axis opposite the laser entrance hole to create a long duration point source of radiation. This would simulate a star turning on, and drive a scaled molecular cloud target package, as shown in Figure 2a. Results from FY11 would aid detailed design work for a final target design, to be fielded in FY12. A complementary proposal for design work funding has also been submitted through the NIF Concept Development proposal process. A key attraction of our proposed experiment is that the required platform largely already exists. We expect to be able to field our Eagle Nebula science experiment with only minimal modifications to the existing platform, and be able to take publishable data with a minimal number of NIF shots. This proposal has also been coordinated with the Nonlinear, Ablative RayleighTaylor proposal from Alexis Casner's group, which also utilizes the Radiation Transport platform. Early qualification efforts will have similar requirements. That team's experiments could be used as a baseline or reference result which excludes directional effects of radiation. Our project would explore the directional effects in great detail.

\section{NIF Facility Requirements}

The proposed Eagle Nebula experiments take advantage of the established Radiation Transport platform. Figure $2 \mathrm{~b}$ shows the Radiation Transport hohlraum and the proposed

\footnotetext{
7 Williams, R.J.R, “ On the instability of D-type ionization fronts”, M.N.R.A.S., 331, 693-706, (2002).

8 Akira Mizuta, Jave O. Kane, Marc W. Pound, Bruce A. Remington, Dmitri D. Rytuov, and Hideaki Takabe, "Hydrodynamic instability of ionization fronts in H-II regions," Ap. J. 621, 803 (March 10, 2005).
} 


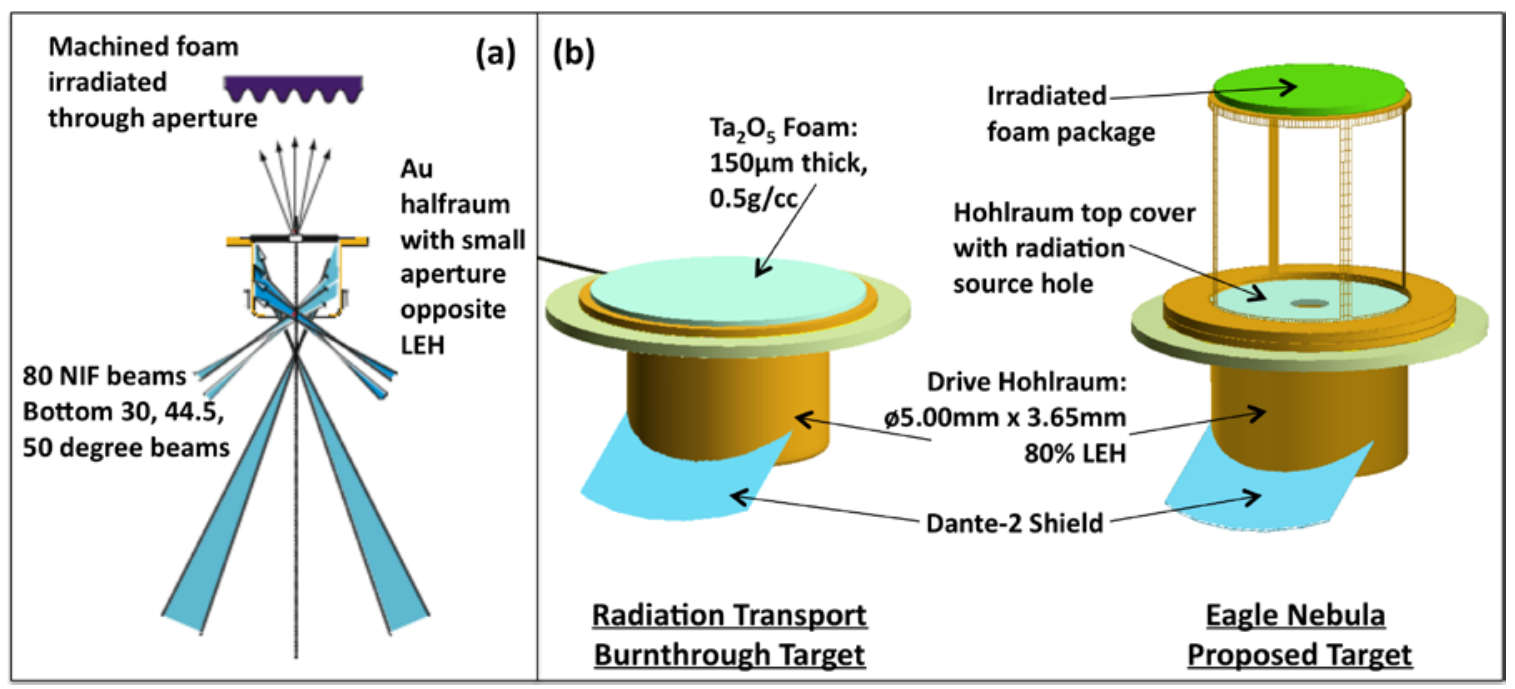

Figure 2: Proposed Eagle Nebula experiment. a) Sketch of experimental setup showing beams and relative features. b) Comparison of the standard Radiation Transport target, shown here for a burn-through experiment, and the proposed Eagle Nebula target.

Eagle Nebula target. Both use the bottom half of NIF to drive a radiation source that ablatively accelerates a package situated above the hohlraum.

The Eagle Nebula experiments require that a hohlraum temperature of $100-150 \mathrm{eV}$ is maintained for 10-50 ns. NIF is the only laser facility capable of generating a radiation pulse of that length with a sufficiently high, sustained radiation temperature and a full suite of imaging diagnostics. A pulse shape of this type would require a total energy of 200-450 kJ in 80 beams, which is within the beam energy limits of NIF. This is longer than any pulse shape currently used in experiments on NIF, and would need to be qualified before full-scale experiments were executed.

This experimental setup will generate a radiation source at the upper, $1 \mathrm{~mm}$ diameter target aperture of approximately $100 \mathrm{eV}$. The irradiated foam pattern is offset from this aperture by $4 \mathrm{~mm}$, lowering the effective temperature at the ablated surface. By integrating the flux at the hohlraum aperture, and assuming this flux expands into $2 \pi$ steradians, we can calculate this effective radiation temperature at the foam surface. Using $F_{\text {rad }}=\sigma T_{\text {rad }}{ }^{4}$, we will have a radiation flux at the hohlraum aperture of $1.03 \times 10^{20}$ $\mathrm{erg} / \mathrm{cm}^{2}$ *sec. Integrated over the aperture, the power emitted will be $8.1 \times 10^{17} \mathrm{erg} / \mathrm{sec}$. The flux at a surface $4 \mathrm{~mm}$ away will be reduced to $8.0 \times 10^{17} \mathrm{erg} / \mathrm{cm}^{2} * \mathrm{sec}$, or an effective radiation temperature of $29.7 \mathrm{eV}$ at the center of the foam. The edges of the foam will initially be only slightly cooler in temperature, but absorption in the ablated plasma will quickly lower the radiation flux that penetrates to the initial outer surface of the foam. Note that in future analysis, a more careful treatment of the time-dependent ablation pressure including the tantalum opacity and drive absorption in the ablated plasma “exhaust” will be utilized in our drive modeling. ${ }^{9}$

\footnotetext{
${ }^{9}$ J.H. Hammer and M. D. Rosen, “A consistent approach to solving the radiation diffusion equation”, Phys. Plasmas 10, 1829 (2003).
} 
Using the effective radiation temperature of $29.7 \mathrm{eV}$ at the foam, the ablation pressure generated is

$$
P_{a b l}=4.4\left(\frac{T_{r a d}}{100 e V}\right)^{3.5} \text { Mbar }=.063 \text { Mbar }
$$

assuming a Planckian spectrum for $T_{r a d}, \gamma=5 / 3$, and where we assume the material temperature is equal to the radiation temperature in the energy deposition layer. ${ }^{10}$ From this, we can expect an acceleration of $g=\frac{P_{a b l}}{\rho h}, \rho$ is the foam density and $h$ is the thickness of the foam feature, which is $6.3 \times 10^{12} \mathrm{~cm} / \mathrm{sec}^{2}$ at the center of the foam pattern for a $200 \mathrm{mg} / \mathrm{cc} \mathrm{Ta}_{2} \mathrm{O}_{5}$ foam that is $500 \mu \mathrm{m}$ thick. A reasonable pattern in the foam could have an amplitude of $5 \mu \mathrm{m}$, and a spacing of $50 \mu \mathrm{m}$. This will give a classical RayleighTaylor growth factor proportional to $\exp \left[\mathrm{n}_{\mathrm{RT}} \mathrm{t}\right]$, where $n_{R T}=\sqrt{A_{n} k g}, A_{n}$ is the Atwood number, which we assume is 1 , and $k$ is the wavenumber of the foam ripple pattern, $2 \pi$ over the pattern spacing, here $50 \mu \mathrm{m}$. For a 50 ns drive on the foam features described above, $n_{R T}=4.5$, for a growth factor of $\sim 90$. This should provide ample growth for clear imaging of the evolution of the foam features.

Side-on backlighting would be used to explore the evolution of the foam features. This backlighter development would be part of the first-year experimental design phase, and would be modeled after the side-lighting setup used in the Radiative SNRT experiments fielded at the end of FY09. These development efforts would focus on choosing an appropriate backlighter and foam material for imaging experiments. See the accompanying NIF proposal for our proposed sidelighter geometry, including how the geometry mitigates unconverted light effects.

In FY11, we require 5 shots to qualify the hohlraum performance for the required long pulse shape and demonstrate the side-on radiography techniques. These shots would measure the laser drive at the laser entrance hole using the lower Dante diagnostic, the radiation source generated at the upper aperture using a combination of the upper Dante diagnostic and the VISAR/SOP diagnostic, and the hohlraum stagnation and LEH closure using the lower SXI. Shots in FY11 would also qualify the side-lighting techniques, using gated imagers (GXDs) and streaked imagers (DISCs) in equatorial DIMs to assess signal-to-noise and resolution. In FY12, we would carry out the Eagle Nebula dynamics experiments, which would require an additional 5 shots using side-on streaked and gated radiography to observe feature evolution of the foam package, possibly simultaneously.

These NIF facility requirements are consistent with the current Radiation Transport platform development. Direct comparisons to the Radiation Transport geometry and pulse shape are included in the NIF proposal template, accompanying this proposal.

A sample shot plan is also included in the accompanying materials. All shots in the plan use existing, qualified, or soon to be qualified NIF diagnostics. Shot opportunities in

\footnotetext{
${ }^{10}$ R.P. Drake, High-Energy-Density Physics: Fundamentals, Inertial Fusion, and Experimental Astrophysics, Springer, New York, 2006.
} 
FY11 would focus first on qualifying a long (10-50 ns) drive pulse, then on qualifying backlighting techniques with long laser delays. Backlighters would be tested for signalto-noise, resolution, and duration for use with equatorial gated and streaked diagnostics. This plan may be modified to include debris testing, if so required. FY12 would begin with a debris test of the full target, including the halfraum, foam pattern and holder, and backlighter. This would be followed by data shots probing different times in the evolution of the foam pattern.

Target fabrication and assembly would rely on techniques successfully implemented by the Radiation Transport Platform. The hohlraum, aperture, LEH shield, backlighter, and foam feature holder are identical or very similar to existing Radiation Transport target components, and could be assembled very precisely using similar tooling. Foam composition, density, and pattern fidelity would need to be carefully characterized, also much like the Radiation Transport targets.

\section{Experimental Team}

Amy Cooper will lead the experimental team at LLNL as Principal Investigator, with Bruce Remington providing input and science direction. Several members of the Radiation Transport experimental and computational (design) team will participate in this effort, including Steve Maclaren, who is the lead designer for the Radiation Transport team experiments, and Alastair Moore and Amy Cooper, who are both experienced NIF shot RIs, practiced in the details of the review processes, campaign management tools, target positioning, laser setup, and diagnostic requests. Akira Mizuta will perform 2D and 3D simulations, and advise on the theory of the directional instability. Mark Foord and John Hayes will provide additional simulation support. Robin Williams, Dmitri Ryutov, and Marc Pound will advise on the relevant astrophysical and hydrodynamic interpretation of the data.

\begin{tabular}{|l|l|l|l|l|}
\hline Name & Affiliation & Email & Phone & Citizenship \\
\hline Bruce Remington & LLNL & remington2@llnl.gov & $925-423-2712$ & USA \\
\hline Amy Cooper & LLNL & cooper64@llnl.gov & $925-423-8942$ & USA \\
\hline Alastair Moore & AWE & moore212@llnl.gov & $925-422-4066$ & UK \\
\hline Steve Maclaren & LLNL & maclaren2@lln..gov & $925-423-0625$ & USA \\
\hline Marc Pound & U. Maryland & mpound@umd.edu & $301-405-1520$ & USA \\
\hline Robin Williams & AWE & robin.williams@awe.co.uk & $44-118-982-6203$ & UK \\
\hline Dmitri Ryutov & LLNL & ryutov1@llnl.gov & $925-422-8932$ & USA \\
\hline Mark Foord & LLNL & foord1@llnl.gov & $925-422-0990$ & USA \\
\hline John Hayes & LLNL & hayes37@llnl.gov & $925-422-1506$ & USA \\
\hline Akira Mizuta & KEK Japan & mizuta@post.kek.jp & $81-29-879-6102$ & Japan \\
\hline
\end{tabular}

Table 1: Eagle Nebula Team. 


\section{Instructions}

1. This template is designed to gather basic facility information regarding experiments proposed under the FY2010 NIF facility time call.

2. The template is broken into 5 sections:

a) Summary of proposed experiment: Desired platform (if known), NIF shots requested, brief campaign description, sketch of experimental configuration

b) Diagnostic requirements

c) Laser requirements

d) Target requirements

e) Other requirements

3. Please fill out each section and keep your answers brief. The NIF team will request additional information as needed from the Principal Investigators. Please attach additional pages to any section as needed.

4. Further information on the facility and the NIF call may be found at:

https://lasers.IInl.gov/for_users/experimental_capabilities/

5. Thank you for your assistance, and please contact the NIF User Office if you have questions. 


\section{Summary of proposed experiment (Page 1 of 3)}

-_Desired platform (If known): c. Radiation Transport

- Number of shots requested: Please fill out table below indicating number of "good data" shots requested each year. Do not add in additional shots to account for contingency, experimental problems, etc; NIF staff will consider this in planning evaluation

\begin{tabular}{|l|c|c|c|l|}
\hline $\begin{array}{l}\text { Summary Shot } \\
\text { Table }\end{array}$ & FY2010 & FY2011 & FY2012 & Comments \\
\hline Total shots & 0 & 5 & 5 & $\begin{array}{l}\text { FY11 to qualify drive } \\
\text { pulse, FY12 data } \\
\text { shots }\end{array}$ \\
\hline
\end{tabular}




\section{Summary of proposed experiment (Page 2 of 3)}

- Brief campaign description (include summary of preparatory shots (drive, diagnostic development, other) and actual data acquisition shots):

We propose to test the initial design concept for a well-scaled HEDLP experiment to quantitatively test the models and 2D simulations of the Eagle Nebula dynamics deep into the nonlinear regime.

The initial design is based on the Radiation Transport platform, and would use a halfhohlraum radiation cavity with a small, possibly tamped opening on the side opposite the laser entrance hole to create a long duration point source of radiation. This would simulate a star turning on, and drive a scaled molecular cloud target package, as shown on Slide 4.

In FY11, we require 5 shots to qualify the hohlraum performance for the required long pulse shape and test side-on radiography techniques. These shots would measure the laser drive at the laser entrance hole using the lower Dante diagnostic, the radiation source generated at the upper aperture using a combination of the upper Dante diagnostic and the VISAR/ SOP diagnostic, and the hohlraum stagnation and LEH closure using the lower SXI.

In FY12, we would carry out the Eagle Nebula dynamics experiments, which would require an additional 5 shots using side-on streaked and gated radiography to observe feature evolution of the foam package, possibly simultaneously. 


\section{Summary of proposed experiment (Page 3 of 3)}

- Sketch of experimental configuration: Pls. provide a simple sketch of the The National Ignition Facility experimental configuration below. Include orientation of target, laser and any backlighter beams, diagnostic sightlines, etc. If configuration is identical to an existing platform so indicate. For further information on existing platforms and chamber geometry see the NIF website:

https://lasers.IInl.gov/for_users/experimental_capabilities/index.php

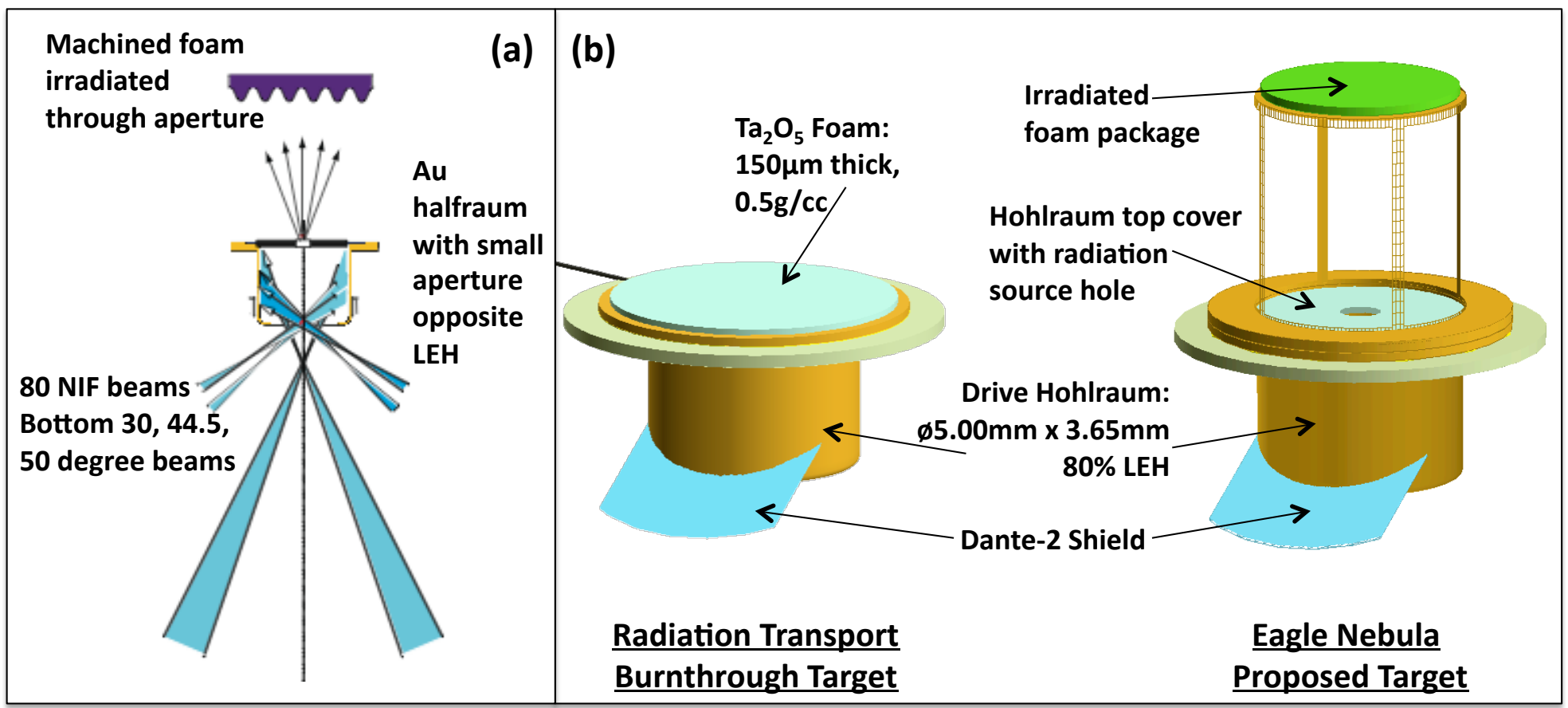

a) Sketch of experimental setup showing beams and relative features. b) Comparison of the standard Radiation Transport target, shown here for a burn-through experiment, and the proposed Eagle Nebula target. 
PI name: (Cooper,Amy) Proposal title: (Eagle Nebula)

FY2011 Sample Shot Plan

\begin{tabular}{|c|c|c|c|c|c|c|c|c|c|c|}
\hline $\begin{array}{c}\text { Shot } \\
\text { Sequence }\end{array}$ & $\mathbf{F Y}$ & Type of shot & Purpose of shot & Shot logic & $\begin{array}{c}\text { Target } \\
\text { description }\end{array}$ & $\begin{array}{c}\text { Target } \\
\text { orientation }\end{array}$ & Primary systems & $\begin{array}{c}\text { Secondary } \\
\text { Systems }\end{array}$ & $\begin{array}{c}\text { FMEA } \\
\text { systems }\end{array}$ & FMEA logic \\
\hline & 4201 & $\begin{array}{l}\text { Backlighter } \\
\text { PQ }\end{array}$ & $\begin{array}{l}\text { Measure drive } \\
\text { and radiation } \\
\text { source } \\
\text { temperatures for } \\
20 \text { ns drive } \\
\text { Measure drive } \\
\text { and radiation } \\
\text { source } \\
\text { temperatures for } \\
20-50 \text { ns drive } \\
\text { Measure drive } \\
\text { and radiation } \\
\text { source } \\
\text { temperatures for } \\
\text { final drive } \\
\text { duration; } \\
\text { measure } \\
\text { radiation } \\
\text { aperture closure } \\
\text { in time } \\
\text { qualify } \\
\text { backlighter } \\
\text { material and } \\
\text { laser energy } \\
\text { qualify } \\
\text { backlighter } \\
\text { material and } \\
\text { laser energy }\end{array}$ & $\begin{array}{l}\text { qualify } 20 \\
\text { ns drive } \\
\text { qualify }>20 \\
\text { ns drive } \\
\text { qualify final } \\
\text { pulse } \\
\text { S/N and } \\
\text { resolution } \\
\text { test } \\
\text { Need to } \\
\text { test foam } \\
\text { opacity? }\end{array}$ & $\begin{array}{l}\text { Half-holhraum } \\
\text { with radiation } \\
\text { aperture or } \\
\text { VISAR } \\
\text { package } \\
\\
\text { Half-holhraum } \\
\text { with radiation } \\
\text { aperture or } \\
\text { VISAR } \\
\text { package }\end{array}$ & $\begin{array}{l}\text { Vertical, with } \\
\text { direct flux } \\
\text { measurement } \\
\text { PH BL/res target } \\
\text { normal on } \\
\text { horizontal axis } \\
\text { PH BL/res target } \\
\text { normal on } \\
\text { horizontal axis }\end{array}$ & $\begin{array}{l}\text { Dante 1, Dante 2, } \\
\text { SXI-L, SXI-U } \\
\text { 4-strip GXD and } \\
\text { DISC with 1-2x } \\
\text { imaging snout } \\
\text { 4-strip GXD and } \\
\text { DISC with 1-2x } \\
\text { imaging snout }\end{array}$ & $\begin{array}{l}\text { GXD at LEH, } \\
\text { SXRI in } \\
\text { PDIM }\end{array}$ & $\begin{array}{l}\text { SXI-L, GXD } \\
\text { at LEH }\end{array}$ & $\begin{array}{l}\text { SXI-L: beams } \\
\text { into LEH, } \\
\text { LEH closure; } \\
\text { GXD: LEH } \\
\text { blowoff } \\
\text { SXI-L: beams } \\
\text { into LEH, } \\
\text { LEH closure; } \\
\text { GXD: LEH } \\
\text { blowoff }\end{array}$ \\
\hline
\end{tabular}


PI name: (Cooper,Amy) Proposal title: (Eagle Nebula)

FY2012 Sample Shot Plan

\begin{tabular}{|c|c|c|c|c|c|c|c|c|c|}
\hline $\begin{array}{c}\text { Shot } \\
\text { Sequence }\end{array}$ & Type of shot & Purpose of shot & Shot logic & $\begin{array}{c}\text { Target } \\
\text { description }\end{array}$ & Target orientation & Primary systems & $\begin{array}{l}\text { Secondary } \\
\text { Systems }\end{array}$ & $\begin{array}{l}\text { ThPNEAtion } \\
\text { systems }\end{array}$ & $\begin{array}{l}\text { ql Ignition Facility } \\
\text { FMEA logic }\end{array}$ \\
\hline 6 & 2012Full Debris & $\begin{array}{l}\text { Measure debris } \\
\text { generation of } \\
\text { backligher and } \\
\text { hohlraum at } \\
\text { sensitive } \\
\text { diagnostic planes }\end{array}$ & $\begin{array}{l}\text { pass debris } \\
\text { review }\end{array}$ & $\begin{array}{l}\text { Full target; half- } \\
\text { hohlraum, foam } \\
\text { pattern, } \\
\text { backlighter }\end{array}$ & $\begin{array}{l}\text { Vertical, with side- } \\
\text { on backlighting }\end{array}$ & $\begin{array}{l}\text { Dante 1, Dante 2, 4- } \\
\text { trip GXD and DISC } \\
\text { with 1-2x imaging } \\
\text { snout }\end{array}$ & SXI-L, SXI-U & $\begin{array}{l}\text { Dante-1, } \\
\text { SXI-L }\end{array}$ & $\begin{array}{l}\text { SXI-L: beams } \\
\text { into LEH, } \\
\text { Dante-1: T_rad } \\
\text { consistent with } \\
\text { qual shots }\end{array}$ \\
\hline 7 & 2012Data & data shot & data shot & $\begin{array}{l}\text { Full target; half- } \\
\text { hohlraum, foam } \\
\text { pattern, } \\
\text { backlighter }\end{array}$ & $\begin{array}{l}\text { Vertical, with side- } \\
\text { on backlighting }\end{array}$ & $\begin{array}{l}\text { Dante 1, Dante 2, 4- } \\
\text { strip GXD and DISC } \\
\text { with 1-2x imaging } \\
\text { snout }\end{array}$ & SXI-L, SXI-U & $\begin{array}{l}\text { Dante-1, } \\
\text { SXI-L }\end{array}$ & $\begin{array}{l}\text { into LEH, } \\
\text { Dante-1: T_rad } \\
\text { consistent with } \\
\text { qual shots }\end{array}$ \\
\hline 8 & 2012Data & data shot & data shot & $\begin{array}{l}\text { Full target; half- } \\
\text { hohlraum, foam } \\
\text { pattern, } \\
\text { backlighter }\end{array}$ & $\begin{array}{l}\text { Vertical, with side- } \\
\text { on backlighting }\end{array}$ & $\begin{array}{l}\text { Dante 1, Dante 2, 4- } \\
\text { strip GXD and DISC } \\
\text { with 1-2x imaging } \\
\text { snout }\end{array}$ & SXI-L, SXI-U & $\begin{array}{l}\text { Dante-1, } \\
\text { SXI-L }\end{array}$ & $\begin{array}{l}\text { SXI-L: beams } \\
\text { into LEH, } \\
\text { Dante-1: T_rad } \\
\text { consistent with } \\
\text { qual shots }\end{array}$ \\
\hline 9 & 2012Data & data shot & data shot & $\begin{array}{l}\text { Full target; half- } \\
\text { hohlraum, foam } \\
\text { pattern, } \\
\text { backlighter }\end{array}$ & $\begin{array}{l}\text { Vertical, with side- } \\
\text { on backlighting }\end{array}$ & $\begin{array}{l}\text { Dante 1, Dante 2, 4- } \\
\text { strip GXD and DISC } \\
\text { with 1-2x imaging } \\
\text { snout }\end{array}$ & SXI-L, SXI-U & $\begin{array}{l}\text { Dante-1, } \\
\text { SXI-L }\end{array}$ & $\begin{array}{l}\text { SXI-L: beams } \\
\text { into LEH, } \\
\text { Dante-1: T_rad } \\
\text { consistent with } \\
\text { qual shots }\end{array}$ \\
\hline 10 & 2012Data & data shot & data shot & $\begin{array}{l}\text { Full target; half- } \\
\text { hohlraum, foam } \\
\text { pattern, } \\
\text { backlighter }\end{array}$ & $\begin{array}{l}\text { Vertical, with side- } \\
\text { on backlighting }\end{array}$ & $\begin{array}{l}\text { Dante 1, Dante 2, 4- } \\
\text { strip GXD and DISC } \\
\text { with 1-2x imaging } \\
\text { snout }\end{array}$ & SXI-L, SXI-U & $\begin{array}{l}\text { Dante-1, } \\
\text { SXI-L }\end{array}$ & $\begin{array}{l}\text { SXI-L: beams } \\
\text { into LEH, } \\
\text { Dante-1: T_rad } \\
\text { consistent with } \\
\text { qual shots }\end{array}$ \\
\hline
\end{tabular}


PI name: (Cooper,Amy) Proposal title: (Eagle Nebula)

\section{Diagnostic requirements}

- Please refer to the diagnostic list on NIF user website:

https://lasers.Ilnl.gov/for_users/experimental_capabilities/diagnostics.php

- List below NIF diagnostics required for your experiment (along with a short summary description of required spatial, temporal, and spectral resolution) or describe what you wish to observe, and NIF staff will match to available diagnostics.

\begin{tabular}{|l|l|l|}
\hline Diagnostic & Requirements & Purpose \\
\hline Dante 1 (143-274) & $50 \mathrm{~ns}$ sweep, $150 \mathrm{eV}$ hohlraum temp. & Measure drive temperature over long pulse \\
\hline VISAR (90-315) & $2 \mathrm{~mm}$ FOV, long sweep & Characterize radiation source at end of halfraum \\
\hline SXI-L (161-326) & Standard magnification and filters & Image beams into LEH to diagnose drive \\
\hline GXD (equatorial DIM) & 200 ps or 500 ps PFM, long inter-strip delay & Image evolution of foam features in side-on radiography \\
\hline DISC (equatorial DIM) & 20 or 50 ns sweep, imaging slit & Image evolution of single foam feature in side-on radiography \\
\hline Dante 2 (64-350) & 50 ns sweep, low radiation temperatures & Time history of apertured radiation source on foam. \\
\hline
\end{tabular}

-Also indicate below if any additional, user provided diagnostics are required. Provide a short summary of the user provided diagnostic below, including a list of all materials to be introduced into the target chamber.

At this time, we plan on using only NIF commissioned diagnostics. 
PI name: (Cooper,Amy) Proposal title: (Eagle Nebula)

\section{Laser requirements (1 of 2)}

\begin{tabular}{|c|c|}
\hline Laser Parameter & Value \\
\hline 1) Platform to be used & Radiation Transport \\
\hline 2) Number of beams required & 96 \\
\hline $\begin{array}{l}\text { 3) } 3 \text { energy desired per beam (Maximum allowed: } 3 \mathrm{~kJ} \\
\text { ( } 2 \text { nsec square); for pulses other than } 2 \text { nsec square provide } \\
\text { plot of desired power vs. time on next page. NIF User Office } \\
\text { will inform users if energy requirements exceed allowable.) }\end{array}$ & 2.5-4.5 kJ/beam \\
\hline $\begin{array}{l}\text { 4) Peak power per beam ( } 350 \mathrm{TW} \text { maximum total peak power } \\
\text { for shaped, ignition-like pulses) }\end{array}$ & $0.19 \mathrm{TW} /$ beam \\
\hline $\begin{array}{l}\text { 5) Pulse shape (up to } 20 \text { nsec duration) (Options: Square, } \\
\text { impulse ( } 88 \text { psec), or shaped; provide plot of desired power } \\
\text { vs. time for shaped pulse on next page) }\end{array}$ & 10-50 ns shaped \\
\hline 6) SSD bandwidth (options- 45 to $90 \mathrm{GHz}, 45 \mathrm{GHz}$ default) & $45 \mathrm{GHz}$ \\
\hline $\begin{array}{l}\text { 7) Focal spot size ( } \sim 250-\mu \mathrm{m} \text { (unconditioned) or } \sim 1-\mathrm{mm} \\
\text { (conditioned)) }\end{array}$ & $\begin{array}{c}\text { Rev } 1 \text { CPP spots, } 1 \mu m \\
\text { conditioned }\end{array}$ \\
\hline $\begin{array}{l}\text { 9) Delays between beams (up to } 10 \text { nsec-all pulses in a quad } \\
\text { must have same delay) }\end{array}$ & No delay in drive: BL TBD \\
\hline 10) Backlighter beam energy, pulse duration & TBD \\
\hline 11) Other specifications & Specify if desired \\
\hline
\end{tabular}


PI name: (Cooper,Amy) Proposal title: (Eagle Nebula)

\section{Laser requirements (2 of 2)}

For shaped pulses, sketch desired power vs. time below:

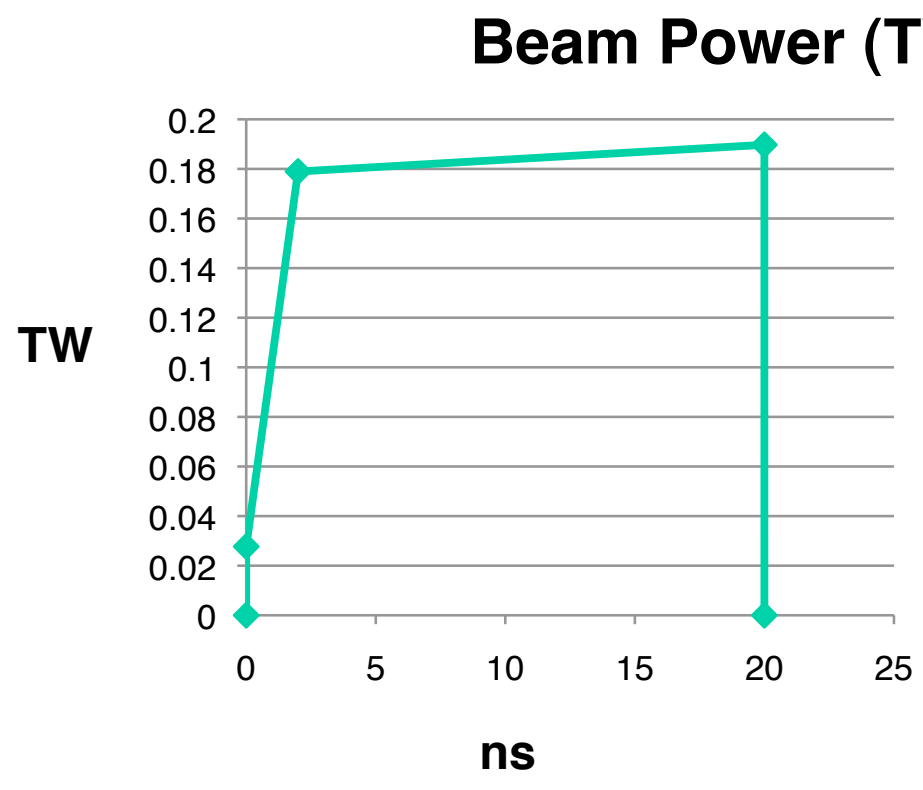

The proposed Eagle Nebula pulse is designed to keep a hohlraum temperature at $100-150 \mathrm{eV}$ for $20 \mathrm{~ns}$, which results in a high-energy but lowpeak-power pulse.

We may wish to validate pulses up to $50 \mathrm{~ns}$ long, with a similar profile. 


\section{Target requirements (summary)}

- List target types required (example: drive measurement; diagnostic test; data acquisition target)

- Drive qualification and radiation source characterization target (to qualify drive temperature for 10-50 ns long drive pulse); standard hohIraum with VISAR package and mirror

- Radiography technique development target: area backlighter, hohlraum, and grid target

- Data target: Standard hohlraum with radiation aperture, foam features on standoff, area backlighter

- For each target type provide a sketch of the target below. Include dimensions and a list of all materials to be used. Also indicate any critical tolerances required, and indicate components (if any) to be provided by the Principal Investigator. 


\section{Target requirements: Drive qualification target}

- For each target type provide a sketch of the target below. Include dimensions and a list of all materials to be used. Also indicate any critical tolerances required, and indicate components (if any) to be provided by the Principal Investigator.

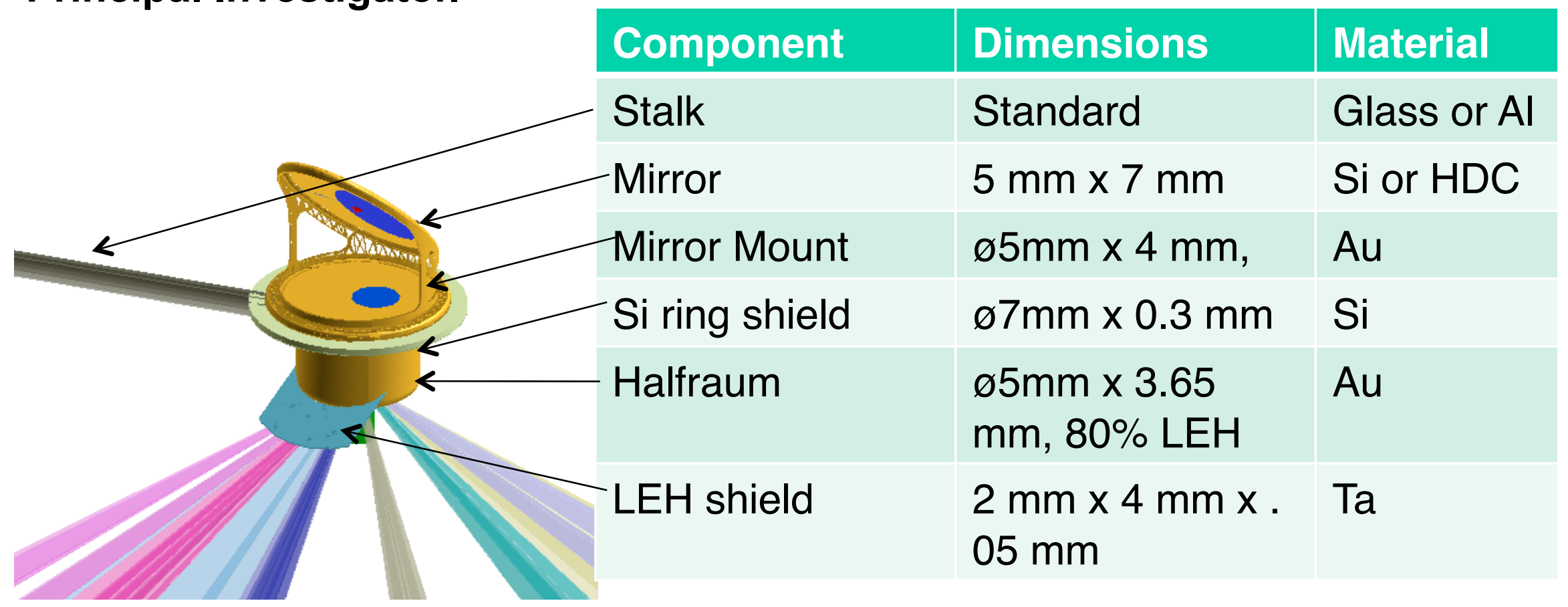




\section{Target requirements: Backlighter PQ}

The National Ignition Facility

- For each target type provide a sketch of the target below. Include dimensions and a list of all materials to be used. Also indicate any critical tolerances required, and indicate components (if any) to be provided by the Principal Investigator.

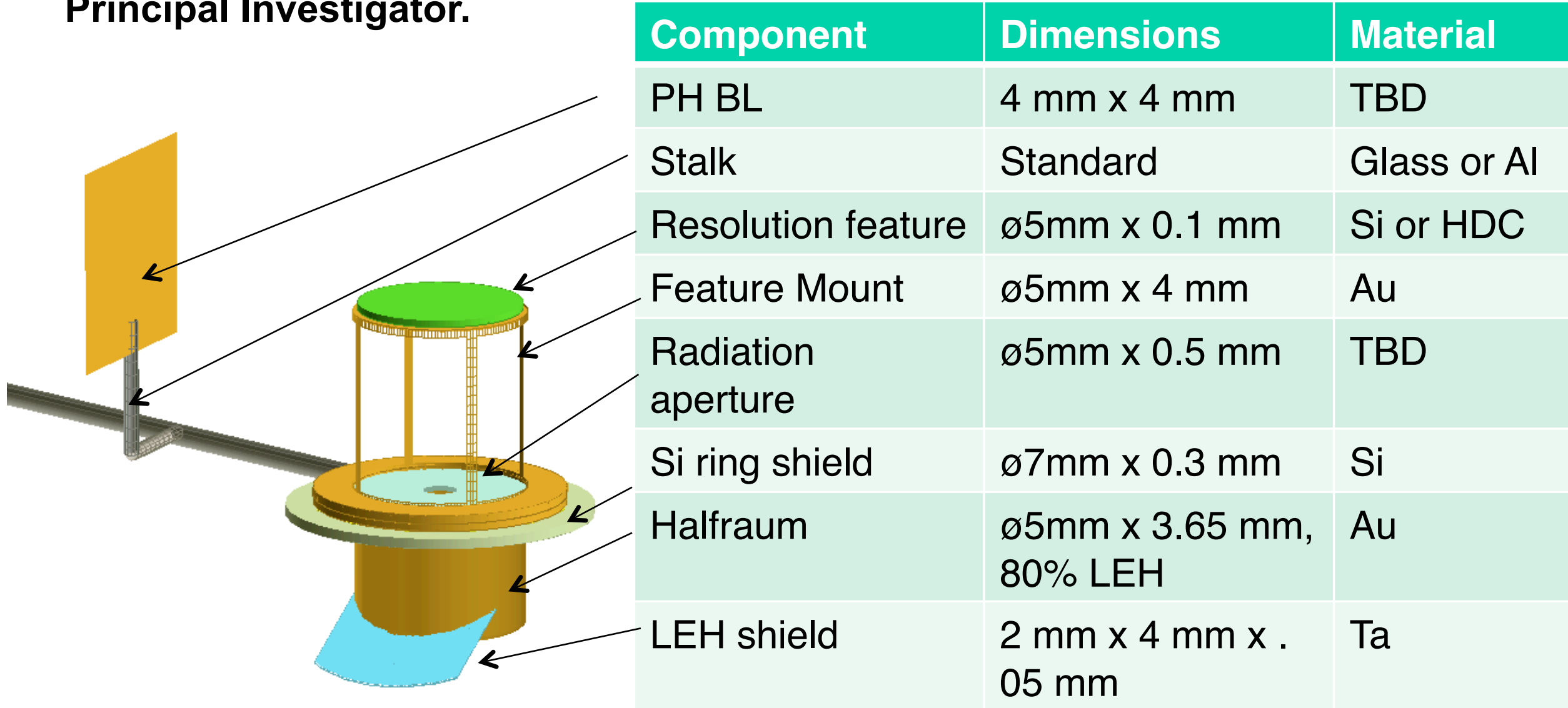




\section{Target requirements: Data Acquisition Target}

The National Ignition Facility

- For each target type provide a sketch of the target below. Include dimensions and a list of all materials to be used. Also indicate any critical tolerances required, and indicate components (if any) to be provided by the Principal Investigator.

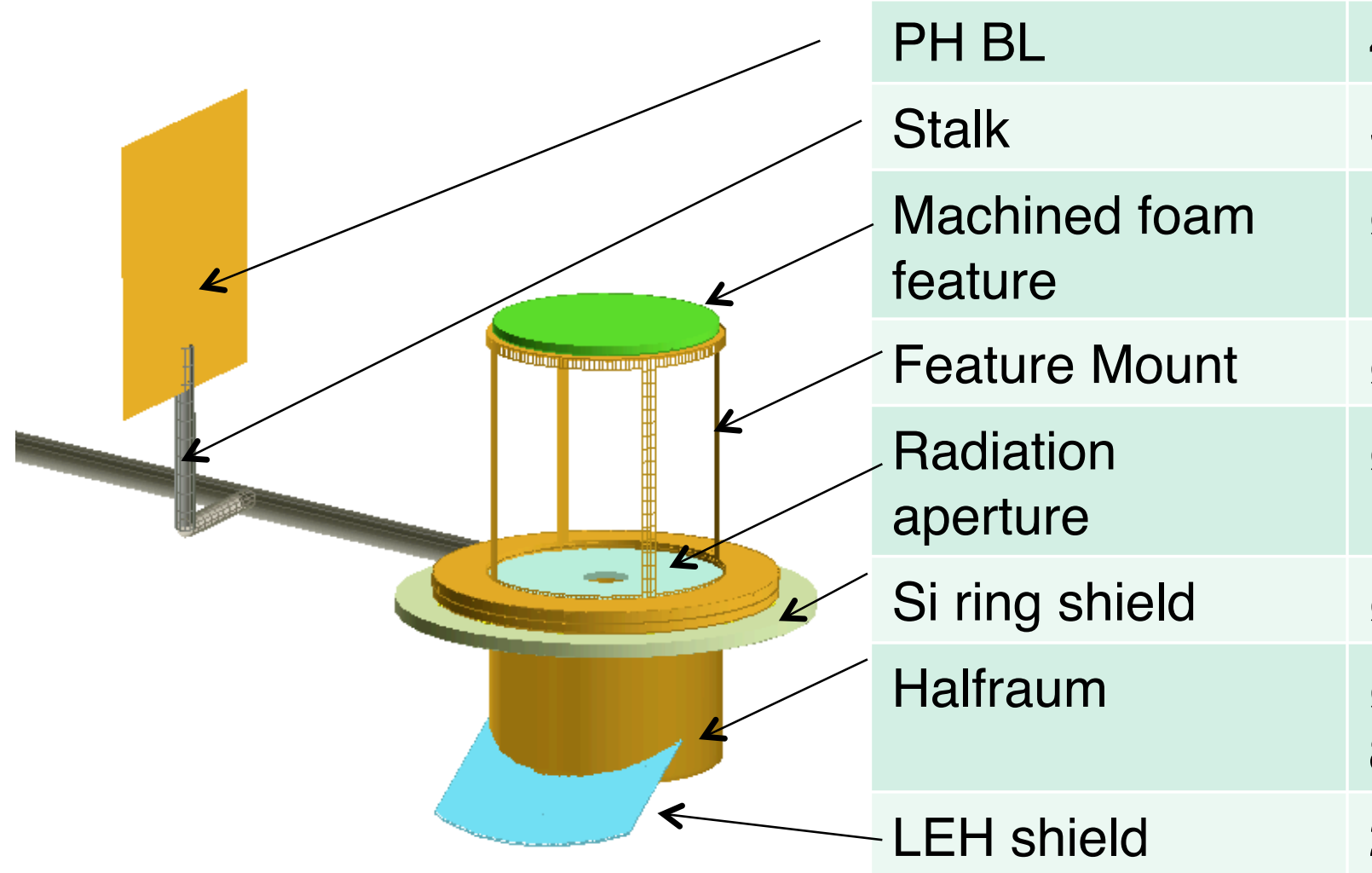

\begin{tabular}{|l|l|}
\hline Dimensions & Material \\
\hline $\begin{array}{l}\text { Standard } \\
\text { ø5m } 4 \mathrm{~mm}\end{array}$ & TBD \\
\hline$\varnothing 5 \mathrm{~mm} 0.3 \mathrm{~mm}$ & Glass or Al \\
\hline$\varnothing 5 \mathrm{~mm} \times 4 \mathrm{~mm}$, & $\mathrm{Au}$ \\
\hline$\varnothing 5 \mathrm{~mm} \times 0.5 \mathrm{~mm}$ & $\mathrm{TBD}$ \\
\hline$\varnothing 7 \mathrm{~mm} \times 0.3 \mathrm{~mm}$ & $\mathrm{Si}$ \\
\hline $\begin{array}{l}\varnothing 5 \mathrm{~mm} \times 3.65 \mathrm{~mm}, \\
80 \% \mathrm{LEH}\end{array}$ & $\mathrm{Au}$ \\
\hline $\begin{array}{l}2 \mathrm{~mm} \times 4 \mathrm{~mm} \times \\
05 \mathrm{~mm}\end{array}$ & $\mathrm{Ta}$ \\
\hline
\end{tabular}


PI name: (Cooper,Amy) Proposal title: (Eagle Nebula)

\section{Target requirements: Data Acquisition Target}

- For each target type provide a sketch of the target below. Include dimensions and a list of all materials to be used. Also indicate any critical tolerances required, and indicate components (if any) to be provided by the Principal Investigator.

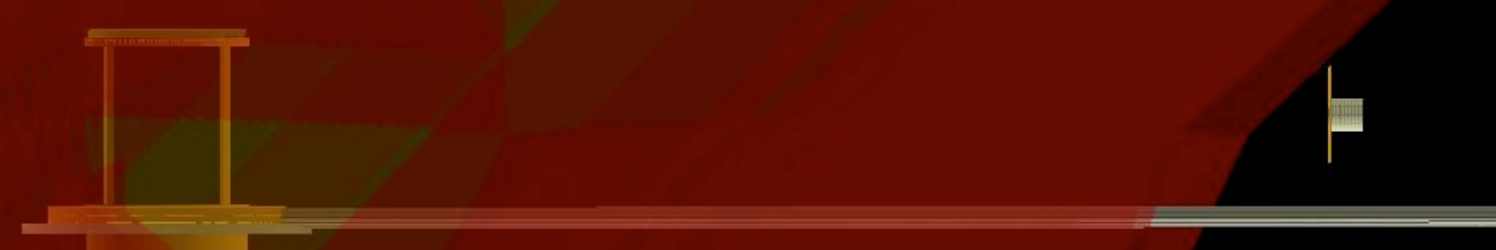

Pinhole backlighter would be placed at $>36 \mathrm{~mm}$ from TCC to avoid all unconverted light from drive beams.

No issues with standard NIF beam pointing limits. 
PI name: (Cooper,Amy) Proposal title: (Eagle Nebula)

\section{Target requirements: Data Acquisition Target}

- For each target type provide a sketch of the target below. Include dimensions and a list of all materials to be used. Also indicate any critical tolerances required, and indicate components (if any) to be provided by the Principal Investigator.

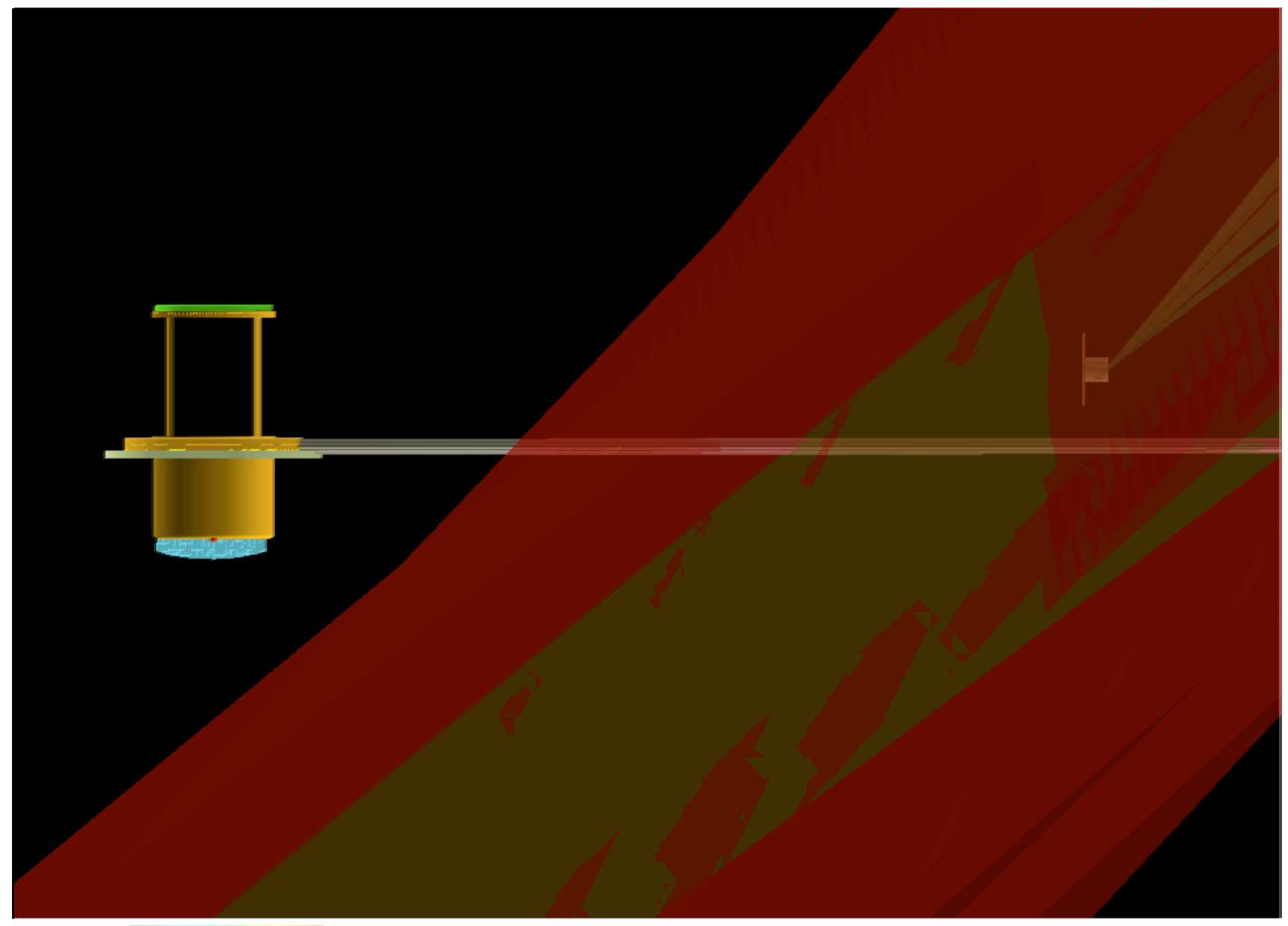

Unconverted light from backlighter beams (here Q31T and Q32T) avoid main target completely; no issues. 
PI name: (Cooper,Amy) Proposal title: (Eagle Nebula)

Supporting materials; Rad Transport pulse and integrated flux for FY09 shots
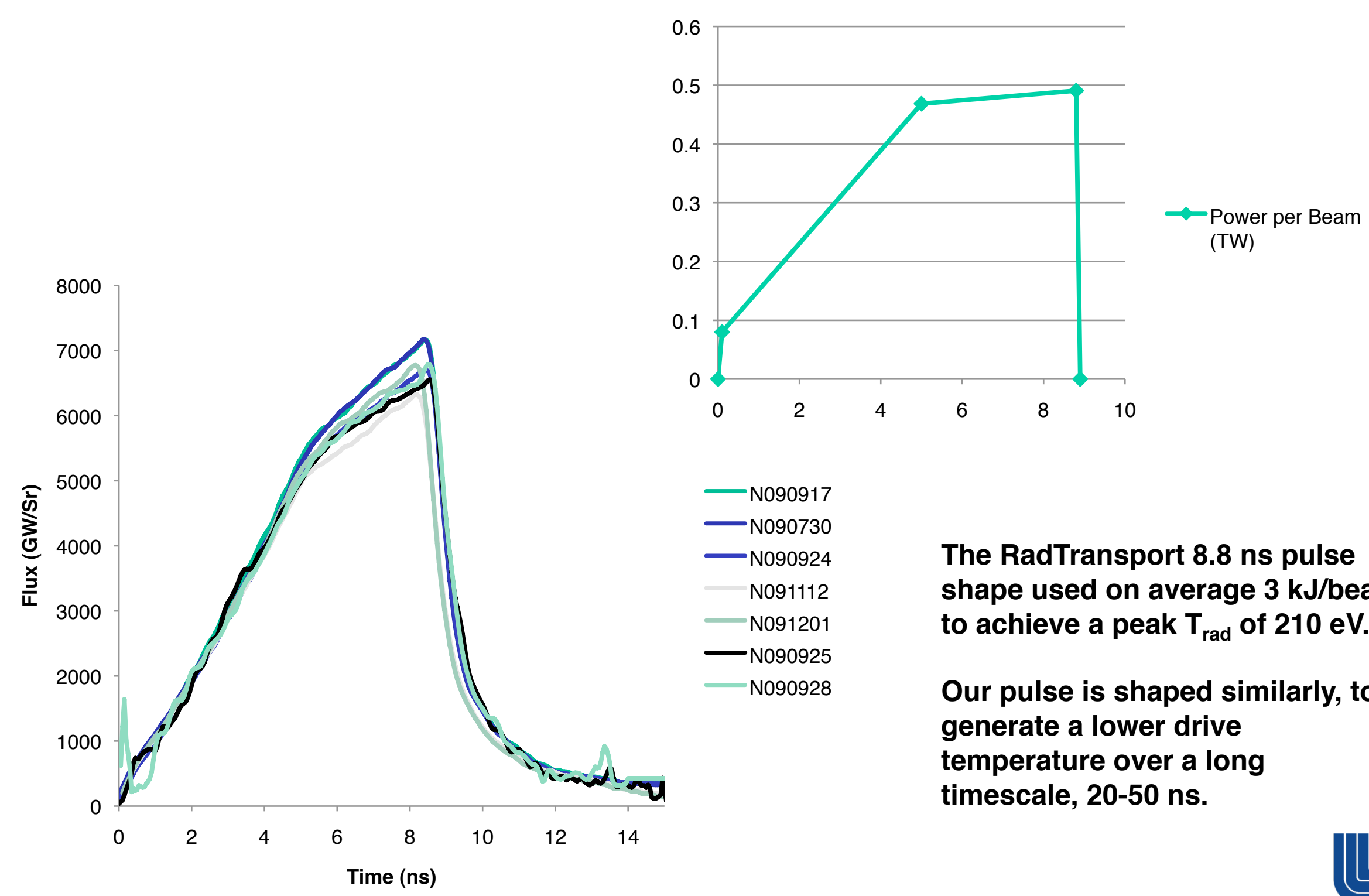

N090730

- N090924

N091112

N091201

- N090925

N090928
The RadTransport 8.8 ns pulse shape used on average $3 \mathrm{~kJ} / \mathrm{beam}$ to achieve a peak $\mathrm{T}_{\text {rad }}$ of $210 \mathrm{eV}$.

Our pulse is shaped similarly, to generate a lower drive temperature over a long timescale, 20-50 ns. 